\section{Susanne Rank}

University of Applied Sciences, Mainz,

\section{Germany}

\section{Teeradej Puapradit}

Assumption University, Bangkok, Thailand

\title{
Case Study about Germans and Thais: Impact of Locus of Control and Organization-Based Self-Esteem on Affective Organizational Commitment \& Job Performance
}

Abstract: Individual self-evaluations like internal locus of control (ILOC) and organization-based self-esteem (OBSE) are discussed as personality traits relevant for positive work behavior of employees. Our case study focuses on the influence of these individual self-evaluations (ILOC \& OBSE) on affective commitment and job performance in the contrary cultural settings of Germans and Thais. To test these assumptions, a case study was conducted with $196 \mathrm{German}$ and Thai students with experience in workplaces. As independent variables ILOC and OBSE 
were assessed, three relevant cultural dimensions were chosen as independent variables: In comparison to Germans, high power distance, femininity and collectivism should be predicted as cultural values of Thais. AOC and self-reported job performance were assessed as dependent variables. Germans and Thais show different levels of three cultural values. Further findings revealed that Germans and Thais have identical levels of OBSE and job performance, but differ in ILOC and AOC. Regression analyses were employed to validate the relationships between the variables. Overall, nationality and masculinity impacted ILOC, whereas OBSE was influenced by masculinity and collectivism. In line with previous research, ILOC and OBSE predict AOC, surprisingly no cultural values impact $A O C$, but nationality does. Based on our hypothesis, job performance was impacted by ILOC, OBSE, AOC, and, however, also by masculinity. The influence of nationality vs. cultural values is not consistent on both dependent variables. Regardless of their German vs. Thai nationality our participants, i.e. highly qualified people, share masculinity as a common value. Confirming previous studies, self-esteem like ILOC and OBSE are valid predictors for commitment and job performance. Limitations and outlook for further research are discussed.

Key words: German vs. Thai culture, locus of control, organization-based self-esteem, affective organizational commitment, job performance.

\section{Introduction}

Leading human capital requires an understanding of drivers for optimizing employees' commitment and job performance in multinational workplaces. Leaders of international companies ask themselves: Are the core self-beliefs of the employees from different countries cultural-bound or not? Are these core self-evaluations drivers for increasing their organizational commitment and their job performance? Following the intercultural research major cultural differences occur between Europe/North America and Asia, confirmed by Hofstede (2001, pp. 79-370) and by House et al. (2004, pp. 235-644). Studies on affective organizational commitment (AOC, Meyer \& Allen, 1991, pp. 61-98; Meyer et al., 2002, pp. 20-52; Tarigan \& Ariani, 2015, pp. 21-42) revealed that $\mathrm{AOC}$ is essential for high-performing companies. Employees with high AOC enjoy working and go for an extra mile (Meyer et al., 1993, pp. 538-551).

Individual self-evaluations like internal locus of control (ILOC) and organization-based self-esteem (OBSE) are discussed as personality traits 
relevant for recruiting and developing the employees (for ILOC: Judge \& Bono, 2001, pp. 80-92; for OBSE: Kanning \& Hill, 2012, pp. 13-21). ILOC drives job performance (see Ng et al. 2006, pp. 1057-1087; for Taiwan: Chen \& Silverthorne, 2008, pp. 572-582). OBSE impacts positive work behavior (e.g. organizational commitment) and fewer turnover intentions (see review of Pierce \& Gardner, 2004, pp. 591-622).

The current case study focuses on the influence of the individual self-evaluations (ILOC \&OBSE) on affective commitment and job performance in the contrary cultural settings of Germans vs. Thais. Previous research found that cultural values like individualism-collectivism impact the ILOC (Spector et al., 2001, pp. 377-397) and OBSE (Tang et al., 2000, pp. 535-559). We predict that these individual traits increase organizational commitment and job performance if the cultural setting supports these core self-beliefs.

\section{Current state of research Cultural comparison of Germans and Thais}

Due to Hofstede (2017, see in figure 1; 2001, pp. 79-370, pp. 476-481) Germans and Thais mainly differ in four of the six cultural dimensions which are power distance (belief in hierarchy), individualism vs. collectivism (focus on work), masculinity (way of communication) and long-term time orientation; all are also confirmed by the Globe project of House et al. (2004, pp. 138-141). 
Figure 1. Cultural values of Hofstede (2017) with $100 \%$ as the highest score

\section{Germany \\ in comparison with Thailand}

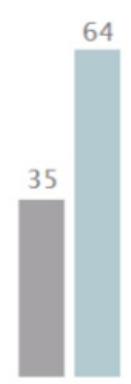

Power Distance

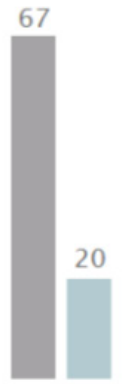

Individualism

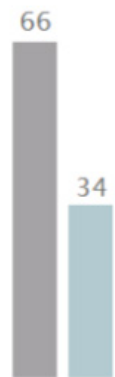

Masculinity

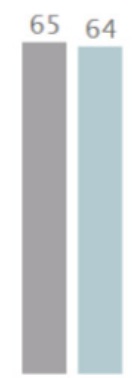

Uncertainty Avoidance

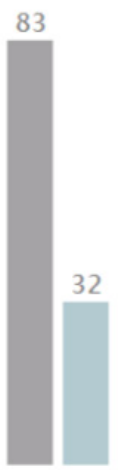

Long Term Orientation

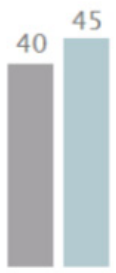

Indulgence

\section{Germany Thailand}

Source: Hofstede, G. (2017). Country Comparison Tool. 2017, Available: https://geert-hofstede.com/ germany.html [20 July 2017].

Long-term orientation is not considered in this study as Smith et al. (1995, pp. 377-400) and Spector (2001, pp. 377-397) only showed impact of these cultural values (i.e. power distance, individualism, masculinity) on ILOC and on OBSE (Pierce \& Gardner, 2004, pp. 591-622). No difference occurs concerning indulgence which is not considered as well. Due to consistent comparisons with previous studies on individual self-evaluations (e.g. Spector, 2001, pp. 377-397), the Hofstede's three dimensions (power distance, individualism, masculinity) are assessed in this case study.

\section{Locus of control}

Rotter (1966, pp. 1-28) explained locus of control (LOC) as an individual's belief concerning control over his environment as an internal locus of control 
(ILOC) vs. external locus of control (ELOC). Levenson (1974, pp. 377-383) introduced a novel version, i.e. IPC scale. Levenson's ELOC (1974, pp. 377-383) in contrast defines two separate dimensional constructs: chance and powerful others. Levenson's scale overcomes the criticism concerning Rotter's scale (1966, pp. 1-28).

Ng et al. (2006, pp. 1057-1087) confirmed the predicted impact of ILOCs on workplace behavior, e.g. job motivation and behavioral job orientation?. Huizing (2015, pp. 76-88) claimed to analyze the validity and reliability of the LOC scale, using it across cultures. Due to the correlational design of most studies, Üzümceker (2016, pp. 149-158) questioned the causal direction of LOC impact on workplace or vice versa, i.e. better job performance enhances the self-belief in one's own capabilities. However, in their longitudinal study Abele \& Spurk (2009, pp. 53-62) found that self-efficacy (closely related variable to ILOC) affected the participants' salary and hierarchical status.

Cross-cultural research on LOC was conducted in several countries (Levenson, 1981, pp. 15-63). American students tended to be more internal-oriented than Japanese students; however, Japanese women tend to perceive their lives as being more controlled by powerful others than men, corresponding to the masculine Japanese culture (Mahler, 1974, pp. 135-139). Smith et al. (1995, pp. 377-400) found in a study with 43 countries that the LOC of Rotter (1966, pp. 1-28) is linked to the high individualism of Hofstede's cultural values. Spector et al. (2001, pp. 377-397) replicated in an intercultural study the results of Smith et al. (1995, pp. 377-400) by a strong correlation between LOC and individualism vs. collectivism. The findings are justified with traditional western values with self-reliance and working hard toward success are highly regarded in countries with western values by disregarding expectations of external forces, i.e. the control from powerful others and chance like in some Asian cultures or in the Middle East. However, Twenge et al. (2004, pp. 308-319) found in a longitudinal study with US college and

\footnotetext{
1. Overlapping with other self-evaluation concepts like generalized self-efficacy (Bandura, 1977, pp. 191-215; Judge \& Bono, 2001, pp. 80-92) and their impact on work behavior is not solved yet.
} 
child samples between 1960-2002 that young Americans showed higher AOC than before, i.e. more individualism and self-serving bias.

Our hypotheses are as follows:

- Cultural values, e.g. high individualism, low power distance and high masculinity, are linked to high ILOC.

- ILOC is a predictor for AOC and job performance in cultures with high individualism and low power distance, i.e. for the Germans as opposed to the Thais.

\section{Organization-based self-esteem}

Self-esteem (see Kanning \& Schnitker, 2004, pp. 112-121) is a personal attitude about to what extent an individual thinks positive or negative himself (Baumeister, 1998, pp. 680-740; Kanning \& Hill, 2012, pp. 13-21). Judge et al. (1997, pp. 151-188) define self-esteem as an aspect of a general self-concept, i.e. core self-evaluations, which includes ILOC, self-efficacy and emotional stability beyond self-esteem. Pierce et al. (1989, pp. 622-648) defined a self-esteem concept for organizational context using the extent to which a person believes he provides a valuable contribution to his organization on three levels of self-esteem: task or situation self-esteem, organization-based self-esteem (OBSE) and global self-esteem (Pierce et al., 1989, pp. 622-648; Gardner \& Pierce, 1998, pp. 48-70).

Impact of OBSE. Pierce \&Gardner (2004, pp. 591-622) summarized that organization-based self-esteem (OBSE) impacts job satisfaction and performance, motivation and commitment with one's own organization (Bowling et al., 2010, pp. 601-626; Gardner \& Pierce, 1998, pp. 48-70; Kanning \& Schnitker, 2004, pp. 112-121; Tang \& Gilbert, 1994, pp. 127-134). OBSE is adopted in this research, which focuses on the context of organization. Accordingly, employees with positive experiences are considered to possess a positive work-related attitude and job performance, while negative experiences will lead to negative job performance and outcomes (Bhana, 2014). 
Cultural impact on OBSE. Sanandaraj \& Thomas (1986, pp. 119-124) identified that masculinity is correlated with high self-esteem; however, a self-developed scale of cultural values is used instead of the Hofstede's one. Van Dyne \& Pierce (2004, pp. 439-459) found a mediating impact of OBSE between collectivism and organizational citizenship in a US sample of a non-profit organization. Tang et al. (2000, pp. 535-559) found a relationship between Japanese culture (with high power distance and collectivism - but not assessed) and OBSE in a Japanese in contrast to the US plant of the same organization. Haar \& Brougham (2016, pp. 720-735) identified in their study with New Zealand European vs. Māori (indigenous people of New Zealand) employees that OBSE influenced job outcomes and mood outcomes of Māoris when compared with New Zealand Europeans. Haar \& Brougham (2016, pp. 720-735) suggest "the implementation of tailored management policies to support cultural differences within New Zealand's diverse workforce".

Our hypotheses are as follows:

- Cultural values, e.g. high power distance, high collectivism and high masculinity impact OBSE.

- OBSE is a predictor for $\mathrm{AOC}$ and job performance in general; cultures with high collectivism, high power distance and high masculinity might support this relationship.

\section{Affective Organizational Commitment}

Allen \& Meyer (1990, pp. 1-18) and Meyer \& Allen (1991, pp. 61-98) defined organizational commitment as "a psychological state that binds an employee to an organization, thereby reducing the incidence of turnover" including three components: affective commitment, continuance commitment, normative commitment. One of these three components is an extraordinary predictor for positive work behavior and in the focus of our study: Affective organizational commitment (AOC) refers to the willingness that makes employees continue 
their employment with the organization. A moderately strong correlation between AOC and citizenship behavior reported by 22 studies suggests the employees' expression of "going the extra mile (Colquitt et al., 2016, p. 67). Meyer et al. (1989, pp. 152-156; 2002, pp. 20-52) indicated a positive relationship between $\mathrm{AOC}$ and work performance; continuance organizational commitment is negatively correlated with work performance. Hence, AOC as a dependent variable is in the focus of this case study.

Cross-cultural effects on AOC. Contradicting results concerning the impact of cultural values on AOC occur: Due to Meyer et al. (2002, pp. 20-52), comparisons of studies conducted within and outside North America show considerably similar results on commitment. No cultural impact on AOC was identified across countries (European study: Vandenberghe et al., 2001, pp. 322-347; worldwide: Gelade, Dobson \& Gilbert, 2006, pp.542-556). However, Andolšek \& Štebe (2004, pp. 181-209) showed that a personal value set in incentives (materialistic vs. post-materialistic: helping others) is more predictive for AOC in individualistic vs. collectivistic countries. In a study in an Indian IT service organization Messner (2013, pp. 76-100) found influence of Globe's values (House et al., 2004, pp. 235-644) on AOC: Power distance is negatively correlated with $\mathrm{AOC}$, in contrast uncertainty avoidance, collectivism, performance and humane orientation are positively related. Afaneh et al. (2014, pp. 129-146) revealed at a Jordanian university that masculinity, individualism and uncertainty avoidance influence commitment. The impact of this study is limited as AOC is combined with normative and continuance commitment into one score in their analysis but three components show different impact on job performance and withdrawal (Meyer et al. 2002, pp. 20-52).

Our hypotheses are as follows:

- Cultural values like low power distance, high collectivism and femininity (similar to humane orientation) impact AOC.

- OBSE and IOC are predictors for AOC, see hypotheses 2. and 4. 


\section{Self-rated Job Performance}

Colquitt et al. (2016, pp. 37-47) define job performance as "the value set of employee behavior that contributes, either positively or negatively, to organizational goal accomplishment". Yousef (2000, pp. 6-28) suggested two dimensions of job performance: quality and productivity. In our study, the self-appraisal technique of Youssef (2000, pp. 6-28) is used because the approach of "self-appraisal technique on quantity and productivity" is proven to yield plausible outcomes (Chen \& Silverthorne, 2008, pp. 572-582). Further, we stick to a cross-sectional study design rather to a survey in one company to assess the cultural values of Germans and Thais instead of a mixture of country and organizational cultures. In contrast to Meyer et al. (2002, pp. 20-52), Yiing \& Ahmad (2008, pp. 53-86) found that organizational commitment significantly correlated with job satisfaction, but not with job performance. Yousef (2000, pp. 6-28) showed in the United Arab Emirates that nationality mediates the relationship between organizational culture, job satisfaction and performance.

Our hypotheses are as follows:

- OBSE, IOC and AOC are predictors for high job performance which might not be impacted by cultural values, as the results of previous studies are mixed.

To sum up, we predict that specific cultural values are linked to individual traits. Next, individual traits as well as specific cultural values increase affective organizational commitment. Job performance is only influenced by traits and AOC.

\section{Materials \& Method}

\section{Sample \& Demographics}

The research is conducted by an online-based survey. 98 Germans and 96 Thais participated. The sample group consists of undergraduate and graduate students who have some work experience in organizations. Of the 
total sample, 49\% ( $\mathrm{N}=96)$ are male respondents and $51 \%(\mathrm{~N}=99)$ female. The respondents between 18-25 years old comprise $32.70 \%(\mathrm{~N}=64)$; the majority belonged to the age of $26-33$ years old, comprising $35.70 \%$ ( $N=$ 70); the minority respondents were between 34-41 years old, comprising $13.30 \%(N=26)$; and the oldest age category, 42-65 years old, accounted for $18.40 \%(N=36) .55 \%(N=108)$ of the participants hold bachelor's degrees; while 44\% ( $N=88$ ) of them hold master's degrees. Regarding occupation, the participants were asked to select their current or former organizational work experience, which is classified in five categories as follows: Managers and senior officials accounted for $20.40 \%(N=40)$, professional occupation (healthcare, teaching, legal professionals) for 18.90\% ( $N=37)$, technical occupations for $12.20 \%(\mathrm{~N}=24)$, administrative and secretarial occupations for $25.50 \%(N=49)$, and sales and customer service occupations for $23 \%(N=45)$.

\section{Measures}

\section{Cultural Values}

The Values Survey Module developed by Hofstede \& Minkov (2013) was employed to measure the variables. The scale uses a 5-point Likert scale, where one was the lowest score and five was is the highest score. The reliability of VRM 2013 was tested by each dimension and values were found to be over .70 (Hofstede \& Minkov, 2013). Three dimensions (power distance, individualism vs. collectivism, masculinity vs. femininity: each with 4items) are applied. Because of our analysis requirements we decided to discard the proposed index formulas of Hofstede \& Minkov (2013). An aggregated value of all items of each dimension are formed for our statistical analysis.

\section{Internal Locus of Control (LOC)}

ILOC is measured by adopting Levenson's IPC Scale (Levenson, 1973, pp. 397-404). Eight items of ILOC scales out of the original 24 items are taken into account. Further, a 6-pointLikert scale is labeled from strongly disagree as 
the lowest score to strongly agree as the highest score; the sum of 8 items represents the ILOC attitude of each participant.

\section{Organizational Based Self-Esteem (OBSE)}

Due to its good reliability (between .86 and .96) and multi-language availability (Kanning \& Hill, 2015, pp. 13-21), the OBSE scale of Pierce et al. (1989, pp. 622-648) is applied with 10 self-assessment items. Each is rated based on a 5 -point Likert scale (1 = "totally disagree" to 5 = "totally agree").

\section{Affective Organizational Commitment}

The AOC scale was developed and validated by Allen and Meyer (1990, pp. 1-18). For the AOC scale a revised version with six items is applied and rated on the basis of a 5-point Likert scale (1 = "totally disagree" to 5 = "totally agree", Meyer et al., 1993, pp. 538-551; Meyer et al., 2002, pp. 20-52).

\section{Self-Appraised Job Performance}

This variable is measured by using Yousef's (2000, pp. 6-28) job performance scale. The scale is self-appraisal approach. The three items are only adopted: quality of your performance, your productivity on the job, How do you evaluate the performance of yourself at your job compared with your peers doing the same kind of work?; the last item How do you evaluate the performance of your peers at your job compared with yourself doing the same kind of work? is excluded because it generated the smallest extraction value; the score did not reflect job performance in previous research. A5-point Likert scale with very low as the lowest score and very high as the highest score was employed.

\section{Results}

\section{Reliability of Scales}

To prove the reliability of each scale, the cronbach's $\alpha$ is calculated. If the cronbach's $\alpha$ is higher than 0.70 (Streiner, 2003, pp. 99-103), an index is ag- 
gregated for each variable. For the ILOC the cronbach's $\alpha$ is .83, regarding OBSE the cronbach's $\alpha$ is .88, for cultural values the cronbach's $\alpha$ for power distance is .85, for individualism.86, for maculinity.86; concerning AOC the cronbach's $\alpha$ is very high with .93, for self-assessed job performance it is the lowest, but still fine at .79. Thus, an index is calculated for each scale.

\section{Test of National Effects}

Based on Spector et al. (2001, pp. 377-397), the first test is to show that the cultural values significantly differ by nationality; all assessed variables are considered by this analysis:

The Germans and the Thais show different levels in all three cultural values analyzing with ANOVA with gender and age as control variables: the Germans show higher individualism (M=4.01, SD=.59) than the Thais $(M=2.33, S D=.49$, $\mathrm{F}(1,192)=454.08, \mathrm{p}<.0001)$ and higher masculinity $(\mathrm{M}=4.16, \mathrm{SD}=.49)$ than the Thais $(M=2.56, S D=.36, F(1,192)=655,14, p<.0001)$. In contrast, the Thais reveal higher power distance $(\mathrm{M}=3.62, \mathrm{SD}=.62)$ than the Germans $(\mathrm{M}=2.04, \mathrm{SD}=.44$, $F(1,192)=409.98, p<.001)$. Gender and age have no significant effect on all cultural values. In addition, a main effect by nationality on the internal locus of control and affective commitment occurred, see figure 2., the Thais show higher value of internal locus of contro/ than the Germans - contrary to our hypothesis 1. As predicted by hypothesis 5., the Thais with higher collectivism reveal higher affective commitment than the Germans with lower collectivism.

Figure 2. Means and standard deviations of AOC, job performance, ILOC \& OBSE by nationality

\begin{tabular}{|l|l|l|l|l|l|}
\hline $\begin{array}{l}\text { Dependent } \\
\text { variables }\end{array}$ & $\begin{array}{l}\text { Nation- } \\
\text { ality }\end{array}$ & M & SD & F & P \\
\hline \multirow{2}{*}{$\begin{array}{l}\text { Affective Com- } \\
\text { mitment }\end{array}$} & German & 2.53 & .76 & $F(1,192)=75.05$ & $p<.0001$ \\
\cline { 2 - 4 } & Thai & 3.56 & .90 & & \\
\cline { 2 - 4 } & Total & 3.05 & .98 & & \\
\hline
\end{tabular}




\begin{tabular}{|c|c|c|c|c|c|}
\hline \multirow{3}{*}{$\begin{array}{l}\text { Self-assessed } \\
\text { Job Perfor- } \\
\text { mance }\end{array}$} & German & 3.78 & .64 & \multirow[t]{3}{*}{$F<1$} & \\
\hline & Thai & 3.75 & .736 & & \\
\hline & Total & 3.77 & .680 & & \\
\hline \multirow{3}{*}{$\begin{array}{l}\text { Internal Locus } \\
\text { of Control }\end{array}$} & German & 4.35 & .68 & \multirow[t]{3}{*}{$F(1,192)=5.21$} & \multirow[t]{3}{*}{$p<.02$} \\
\hline & Thai & 4.58 & .84 & & \\
\hline & Total & 4.46 & .77 & & \\
\hline \multirow{3}{*}{$\begin{array}{l}\text { Org. Based } \\
\text { Self-esteem }\end{array}$} & German & 3.80 & .53 & \multirow[t]{3}{*}{$F<1$} & \\
\hline & Thai & 3.79 & .62 & & \\
\hline & Total & 3.79 & .57 & & \\
\hline
\end{tabular}

Source: own statistical Anova analysis via SPSS.

No effect of gender on the mentioned variables emerges. A significant main effect of age occurs for $A O C$ with $F(1,192)=5.21, p<.02$ : The participants between 26-33 years show the highest $\mathrm{AOC}$ of all the groups, see figure 3 .

Figure 3. Means and standard deviations of affective commitment by age groups

\begin{tabular}{|l|l|l|}
\hline Age & Mean & SD \\
\hline $18-25$ & 2.96 & .89 \\
\hline $26-33$ & 3.31 & .88 \\
\hline $34-41$ & 2.97 & 1.19 \\
\hline $42-65$ & 2.74 & 1.06 \\
\hline Total & 3.05 & .98 \\
\hline
\end{tabular}

Source: own statistical analysis via SPSS.

\section{Impact of Cultural Values on ILOC and OBSE}

To test the cultural effects on the ILOC of Germans and Thais, separate regression analyses for Germans and Thais are conducted by including power distance, masculinity and individualism as predictors, as well as gender and age as control variables, see hypotheses 1 . and 2.:

For Germans, only a significant beta coefficient for high masculinity on ILOC occurs: beta=.26, t(97) $=2.62, p<.01, R 2=0.10$; the other betas are not 
significant. For Thais, two betas are significant: for high masculinity on ILOC with a beta $=.24, t(97)=2.41, p<.02, R 2=0.12$ and a surprising gender effect on ILOC (beta=-.23, $\mathrm{t}=-1.26, \mathrm{p}<.0 .26)$ : The Thai men show a higher ILOC $(\mathrm{M}=4.81$, $\mathrm{SD}=.65)$ than the Thai women $(\mathrm{M}=4.38, \mathrm{SD} .92)$.

Besides the significant effect of nationality on ILOC (beta=.63, t(195) =3.07, $\mathrm{p}<.002, \mathrm{R} 2=.1)$, a high masculinity impact on ILOC is confirmed by an overall regression analysis (beta=.51, t(195) =3.46, $\mathrm{p}<.001, \mathrm{R} 2=.01$. No significant betas for power distance, individualism, age or gender occurred - in contrast to our hypothesis 1 for individualism.

Cultural effects on OBSE are tested with separate regression analyses for Germans and Thais. For the Germans, a significant beta coefficient for high masculinity on OBSE occurs (beta=.31, t(97)=3,26, $p<.002, \mathrm{R} 2=0.21$ ), a significant negative beta for high collectivism (negative to individualism) on OBSE (beta=.-26, t(97) =-2.70, $\mathrm{p}<.008$ ), and a significant, negative beta for age on OBSE (beta=.-28, t(97) =-2.93, p<.004). The younger the Germans are; the more self-esteem they have. Other betas are not significant. For the Thais, a significant beta coefficient for high masculinity on OBSE occurs (beta=.26, $\mathrm{t}(97)=2,57, \mathrm{p}<.01, \mathrm{R} 2=0.13)$, and an almost significant, but negative beta for individualism (i.e. high collectivism) on OBSE (beta=-.19, t(97) =-1.96, p=.05).

In the overall regression analysis on OBSE, no significant betas occur for nationality in contrast to predictors for ILOC; but a strong significant beta coefficient for high masculinity on OBSE occurs (beta=.59, t(195)=4.07, p<.01, $\mathrm{R} 2=0.13$ ), as well as a significant negative beta for high collectivism (negative to individualism) on OBSE (beta=-.38, t(195) =-3.05, p<.003).

\section{Predictors for $\mathrm{AOC}$ and Job Performance}

The impact of the independent variables on AOC are first tested in a separate national regression analysis. For the Germans, a significant impact of high OBSE on AOC occur (beta=.37, t(97)=2.876, $p<.005, \mathrm{R} 2=0.33$ ), as well as a significant impact of age on AOC (beta=-.18, t(97)=-2.00, p<.05). Other betas (ILOC, culture values, gender) are not significant. For the Thais, 
a significant impact of high OBSE on AOC (beta=.48, t(97)=3.91, p<.0001, R2= 0.40) and a significant impact of age on AOC occur (beta=-.18, t(97)=-2.00, $\mathrm{p}<.05$ ). Other betas (ILOC, culture values, gender and age) are not significant.

The overall regression analysis revealed that, in contrast to our hypotheses, nationality significantly influences AOC (beta=.38, t(195) =2.50, $p<.01$ ). As predicted, ILOC impacts AOC (beta=.16, t(195)=2.20, p<.03, R2=0.53) and OBSE influences AOC (beta=.38, t(195)=5.15, p<.0001).

Predictors for self-assessed job performance. As no national or cultural impacts are predicted, first an overall regression analysis was calculated. In line with our hypothesis 7, high ILOC (beta=.22, t(195)=2.52, $p<.01$, R2= 0.37), high OBSE (beta=.11, t(195)=2.24, p<.03) and high AOC (beta=.18, $t(195)=2.98, p<.003)$ significantly impact the self-rated job performance. In addition, high masculinity influences high job performance (beta=.34, $t(195)=2.57, p<.01)$. High power distance failed the significance level for influencing job performance (beta=.20, t(195)=1.92, $p=.056)$. However, no influence of individualism, gender, age or nationality occurred. Even though no national impact on job performance is revealed in this overall regression analysis, we calculate separate regression analyses to follow the previous analysis pattern to understand the predictors on job performance for both national samples. For the Germans, only high ILOC (beta=.31, t(97)=2.70, $p<.0008, R 2=0.40)$ significantly impacts the self-rated job performance. No other influences of OBSE, AOC, masculinity, power distance, individualism, gender, age or nationality occurred. For the Thais, our hypothesis 7 is confirmed, as high AOC (beta=.27, t(97)=2.50, $p<.02, \mathrm{R} 2=.38$ ) significantly impacts the self-rated job performance. High masculinity (beta=. 17, $t(97)=1.94, p=.54)$ and power distance (beta=. 17, $t(97)=1.95, p=.54$ ) failed the significance level for influencing job performance. No influence of ILOC, OBSE, individualism, gender or age occurred. However, as nationality is not a significant predictor for job performance, the separate results of the regression analysis for the Germans vs. the Thais are not valid for further discussion. 
To identify whether our predictors (i.e. nationality, cultural values, self-beliefs) are inter-correlated or independent of one another, a factor analysis with varimax-rotation is conducted. Two independent factors are detected: The first factor (cultural value set) explains 56.31\% of the total variance formed by nationality (eigenvalues: .97), masculinity (eigenvalue: -.91), power distance (eigenvalue: -.88) and individualism (eigenvalue: -.91). The second factor (self-esteem) is based on ILOC (eigenvalue: .90) and OBSE (eigenvalue: .93) and explains28.42\% of the variance. Thus, Hofstede's studies (2001) are confirmed; there is a strong independent factor of the country's cultural values including nationality explaining more than $50 \%$ of the total variance. In addition, a second factor of self-esteem emerged, but explaining less of the total variance than the first factor. These two independent factors are relevant to consider for recruiting and developing the right talents in international companies. However, both factors with their various sub-factors (nationality, different cultural values (i.e. PD; M-F, I-C), locus of control and self-esteem impact positive work behavior differently, i.e. operationalized by AOC and job performance in this study.

\section{Final Remarks}

The nationality of Germans vs. Thais significantly impacts three variables (cultural values, ILOC, and AOC) except OBSE and job performance. Interestingly, the younger people are more affective committed to their organizations than the older ones, which might be explained by the daily work routine of older people after working at organizations for years. The Thais are more affective committed than the Germans, even though Asians leave companies more frequently (10\%average turnover rate) than the Germans (Europe: 6\%average turnover rate, Mercer's Turnover Survey, 2015). Further studies (the Nation, 2013; Turongsomboon \& Pillai, 2016) report the same direction that average turnover rate for Asians is higher than Europeans recently, especially for Thailand the turnover was 13\%, comparing globally. Their junior 
management is the most vulnerable group for voluntary turnover. Suggested from Hay Group's study (Chulajata, 2012), this phenomenon resulted from the government wage's policy and the free flow of labor due to ASEAN Economic Community (AEC). Due to the historical and political impact, the collectivist perspective is valued more in Asia than in Europe (Hofstede, 2013). Due to Meyer et al. (2002, pp. 20-52), AOC leads to lower turnover in organizations. This opposing result should encourage the conducting of a future study at a company by comparing the employee survey data of different age groups concerning self-esteem, $\mathrm{AOC}$ and turnover.

The impact of cultural values on core self-beliefs is partly confirmed: High masculinity predicts higher ILOC and OBSE, even though the Germans show higher masculinity than the Thais. Focusing on achievements in business (high masculinity) enables a strong belief in one's own capabilities and self-esteem (ILOC \& OBSE) regardless of the level of masculinity between the Germans and the Thais. However, this does not support our hypothesis 2., contrary to previous ILOC studies of Smith (1995, pp. 377-400) and Spector (2001, pp. 377-397) in which individualism impacts ILOC.

Confirming our hypothesis 3, OBSE is influenced by collectivism in line with Van Dyne et al. (2004, pp. 439-459) and by masculinity accord to Sanandaraj \& Thomas (1986, pp. 119-124). Surprisingly, nationality only influences ILOC, but not OBSE; this result was not expected. However, ILOC and OBSE are highly correlated ( $r=.70, p<.001$ for ILOC and OBSE); both form one factor in the factor analysis supporting the general self-efficacy concept (Judge \& Bono, 2001, pp. 80-92). In general, international managers should place an emphasis on hiring and developing people with high self-esteem (high ILOC, high OBSE) and high masculinity regardless of their nationality.

For managers in international companies deploying highly qualified people, the most interesting results are that the self-esteem and nationality influence AOC: Supporting our hypotheses 2 and 4, overall core self-evaluations, i.e. high ILOC and high OBSE, predict high AOC. Our results confirm the previous results for ILOC by Ng et al. (2006, pp. 1057-1087) and of the 
OBSE by Pierce \& Gardner (2004, pp. 591-622). Contrary to our hypothesis 3, cultural values do not influence AOC, but nationality does: The Thais show higher AOC than the Germans. Further, the younger Germans show higher $\mathrm{AOC}$ than the older Germans, in line with the generational review about the self-confident generation Y (Twenge et al., 2010, pp. 1117-1141). Surprisingly, in the country-by-country analysis, OBSE and age only predict AOC, but no longer predict ILOC. OBSE might be a stronger success factor for hiring and developing highly qualified people.

Due to hypothesis 6, the core evaluations (ILOC and OBSE) and AOC impact the self-assessed job performance confirming the ILOC analysis of Ng et al. (2006, pp. 1057-1087), the OBSE review of Pierce \& Gardner (2004, pp. 591-622), and the AOC studies of Meyer et al. (2002, pp. 20-52), and Yousef (2000, pp. 6-28). Additionally the cultural value masculinity impacts the self-rated job performance, but is not assumed by our hypotheses: This strong belief and communication style in capabilities and results drives high ratings of job performance. The results discussed need to be considered carefully, as no objective measures of job performance (e.g. turnover of sales representative) are assessed in our case study.

Further limitations of our case study are that the revealed results are restricted to highly qualified people, as our sample only includes academics with work experience. A small sample of 196 people was analyzed from a case study perspective. Future studies with large sample sizes and different levels of qualification are necessary to prove our results. In assessing both self-esteem components a future study should focus on more nationalities than the assessed one. A final limitation is that our case study is based on a correlational design rather than an experimental one (like the vignette task of Dries et al., 2008, pp. 907-928).

In a nutshell, in line with previous research, ILOC and OBSE predict AOC, and surprisingly cultural values do not impact AOC, but nationality does. In our case study, high AOC is bound by high self-esteem and the Thai nationality, which needs to be considered by HRM to enhance the drivers for 
increasing AOC. Based on our hypothesis, job performance was impacted by ILOC, OBSE and AOC, but by masculinity as well. Therefore, the influence of nationality and cultural values on those we assessed is not comparable. Cultural values like masculinity are shared among highly qualified people regardless of nationality. Speculatively assumed masculinity might be a core value/belief of one's own self-concept/personality (like achievement, self-enhancement of Schwartz et al, 2012, pp. 663-688) rather than a cultural value as proposed by Hofstede (2017). Self-esteem like OBSE is a powerful predictor for affective commitment and in addition ILOC and OBSE are predictors for job performance. But ILOC and OBSE are more culturally bound than affective commitment.

As a research outlook, cultural bias is possible for self-esteem evaluations. Contrary to our results, the study of Cai et al. (2007, pp. 162-170) revealed that the Chinese show lower self-esteem than Americans only on cognitive self-evaluation, but on affective self-esteem evaluations American and Chinese show similar affective self-liking. Cai et al. (2007, pp. 162-170) showed that the measures of self-esteem are augmented on the cognitive vs. affective dimensions to figure out where the cultural effects occur. This might solve our dilemma of the different effects of national and cultural values. Future studies might expand the design by explicit vs. implicit measures of self-esteem. 


\section{References}

Abele, A. \& Spurk, D. (2009) The longitudinal impact of self-efficacy and career goals on objective and subjective career goals. Journal of Vocational Behavior, vol.74, pp. $53-62$.

Afaneh, J.A., Khaireddin, M.A., Sanjuq, G.M., \& Qaddoumi, J.B. (2014). Impact of cultural dimensions according to Hofstede model on organizational commitment of the middle management at Jordanian private universities. European Journal of Business and Social Sciences, vol. 3, no. 9, pp. 129-146.

Allen, N.J., \& Meyer, J.P. (1990) The measurement and antecedents of affective, continuance and normative commitment to the organization. Journal of Occupational Psychology, vol. 63, pp. 1-18.

Almutairi, D.O. (2016) The Mediating Effects of Organizational Commitment on the Relationship between Transformational Leadership Style and Job Performance. International Journal of Business and Management, vol. 11, no.1, pp. 231-241.

Andolsek, D.M. \& Stebe, J. (2004) Multinational Perspectives on Work Values and Commitment. International Journal of Cross Cultural Management, vol. 4, no. 2, pp. 181-209.

Bandura, A. (1977) Self-efficacy: Toward a unifying theory of behavioral change. Psychological Review, vol. 84, pp. 191-215.

Baumeister, R.F. (1998). "The self", in Gilbert, D.T., Fiske, S.T. and Lindzey, G. (Eds). In The Handbook of Social Psychology (pp. 680-740). Boston, MA: McGraw-Hill. 
Bhana, S. (2013). The Relationship between Perceived Discrimination, Organisation-Based SelfEsteem (OBSE) and Job Satisfaction among Women at Work. Johannesburg: University of the Witwatersrand. Available: http://hdl.handle.net10539/13436 [25Aug 2016].

Bowling, N.A., Eschleman, K.J., Wang, Q., Kirkendall, C., \& Alarcon, G. (2010). A meta-analysis of the predictors and consequences of organization-based self-esteem. (83, Ed.) Journal of Occupational and Organizational Psychology, vol. 83, no. 3, pp. 601-626.

Cai, H., Jonathon D., Brown, J.D, Deng, C. \& Oakes, M.A. (2007) Self-esteem and culture: Differences in cognitive self-evaluations or affective self-regard? Asian Journal of Social Psychology, vol. 10, pp. 162-170.

Chen, J.-C., \& Silverthorne, C. (2008) The impact of locus of control on job stress, job performance and job satisfaction in Taiwan. Leadership \& Organization Development Journal, vol. 29, no. 7, pp. 572-582.

Chulajata, T. (2012) Asia and Thailand Reward Trends 2011-2012. Thailand: Hay Group. Available: http://www.haygroup.com/Downloads/th/misc/Reward_trend_forum2011(mar2012)_Final.pdf [14 July 2017].

Colquitt, J., LePine, J., \& Wesson, M. (2016) Organizational Behavior: Improving Performance and Commitment in the Workplace (5 ed.). Irwin/McGraw-Hill, pp. 37-67

Dries, N., Pepermans, R. \& De Kerpel, E. (2008) Exploring four generations' beliefs about career: Is "satisfied" the new "successful"? Journal of Managerial Psychology, vol. 23, no.8, pp. 907-928.

Gardner, D.G., \& Pierce, J.L. (1998). Self-esteem and self-efficacy within the organizational context: An empirical examination. Group and Organizational Management, vol. 23, pp. 48-70. 
Gelade, G.A., Dobson, P. \& Gilbert, P. (2006). National differences in organizational commitment: Effect of economy, product of personality, or consequence of culture? Journal of Cross-Cultural Psychology, vol. 37, no. 5, pp. 542-556.

Haar, JM., \& Brougham, D. (2016). Organizational-based self-esteem: A within country comparison of outcomes between Māori and New Zealand Europeans. Journal of Management and Organization, vol. 22, no. 5, pp. 720-735.

Hofstede, G. (2001). Culture's Consequences: Comparing Values, Behaviors, Institutions and Organizations across Nations. Thousand Oaks, CA: Sage.

Hofstede, G. (2017). Country Comparison Tool. 2017, https://geert-hofstede.com/ germany.html [20 July 2017].

Hofstede, G., Hofstede, G. J., \& Minkov, M. (2010). Cultures and Organizations: Software of the Mind (3 ed.). New York: McGraw-Hill.

Hofstede, G., \& Minkov, M. (2013) VALUES SURVEY MODULE 2013. Geert Hofstede BV. Available: http://geerthofstede.com/research-and-vsm/vsm-2013, [20 July 2017].

House, R.J, Hanges, P.J., Javidan, M., Dorfman, P. W. \& Gupta, V. (2004). Culture, Leadership and Organizations. Sage Publications.

Huizing, R. (2015). Who's controlling locus of control? Cross-cultural loc usage. International Journal of Leadership Studies, vol. 9, no.1, pp. 76-88.

Judge, T.A., \& Bono, J.E. (2001) Relationship of core self-evaluation traits - self-esteem, generalized self-efficacy, locus of control, and emotional stability - with job satisfaction and job performance. Journal of Applied Psychology, vol. 86, pp. 80-92. 
Judge, T.A., Locke, E.A., \& Durham, C.C. (1997) The dispositional causes of job satisfaction: A core evaluations approach. Research in Organizational Behavior, vol. 19, pp. 151-188.

Kanning, U.P. \& Hill, A. (2012) Organization-based self-esteem scale-adaptation in an international context. Journal of Business and Media Psychology, vol. 3, no. 1, pp. 13-21.

Kanning, U.P., \& Schnitker, R. (2004) Übersetzung und Validierung einer Skala zur Messung des organisationsbezogenen Selbstwertes. Zeitschrift für Personalpsychologie, vol. 3, pp. 112-121.

Levenson, H. (1973) Multidimensional locus of control in psychiatric patients. Journal of Consulting and Clinical Psychology, vol. 41, pp. 397-404.

Levenson, H. (1974) Activism and powerful others: Distinctions within the concept of internal-external control. Journal of Personality Assessment, vol. 38, pp. 377-383.

Levenson, H. (1981) Differentiating among internality, powerful others, and chance, in: H. Lefcourt (Ed.), Research with the Locus of Control Construct. New York: Academic Press, vol. 1, pp. 15-63.

Mahler, I. (1974) A comparative study of locus of control. Psychologia, vol. 17, pp. 135-139.

Mercer (2015). Turnover Survey 2015. Available: https://www.mercer.com/content/ dam/mercer/attachments/global/webcasts/trends-and-drivers-of-workforce-turnover-results-from-mercers-2014-turnover-survey.pdf, [06 July 2017].

Messner, W. (2013). Effect of organizational culture on employee commitment in the Indian IT services sourcing industry. Journal of Indian Business Research, vol. 5, no. 2, pp. 76-100. 
Meyer, J.P. \& Allen, N.J. (1991). A three-component conceptualization of organizational commitment. Human Resource Management Review, vol. 1, no. 1, pp. 61-98.

Meyer, J.P., Allen, N.J., \& Smith, C.A. (1993) Commitment to organizations and occupations: Extension and test of a three-component conceptualization. Journal of Applied Psychology, vol. 78, pp. 538-551.

Meyer, J.P.S.V., Paunonen I.R., Gellatly R.D., Goffin J., \& D.N.J. (1989) Organizational Commitment and Job Performance: It's the Nature of the Commitment That Counts. Journal of Applied Psychology, vol. 74, pp. 152-156.

Meyer, J.P, Stanley, D.J., Herscovitch, L. \& Topolnytsky, L. (2002) Affective, Continuance, and Normative Commitment to The Organization: A Meta-Analysis of Antecedents, Correlates, and Consequences. Journal of Vocational Behavior, vol. 61, no. 1, pp. 20-52.

Ng, T.W.H., Sorensen, K.L. \& Eby, L.T. (2006) Locus of control at work: a meta-analysis. Journal of Organizational Behavior, vol. 27, pp. 1057-1087.

Pierce, J.L., \& Gardner, D.G. (2004) Self-esteem within work and organizational context: A review of the organization-based self-esteem literature. Journal of Management, vol. 30, pp. 591-622.

Pierce, J.L., Gardner, D.G., Larry, L., Dunham, C.B., \& Dunham, R.B. (1989). Organization-Based Self-Esteem: Construct Definition, Measurement, and Validation. The Academy of Management Journal, vol. 32, no.3, pp. 622-648.

Rotter, J.B. (1966) Generalized expectancies for internal versus external control of reinforcement. Psychological Monographs: General and Applied, vol. 80, pp. 1-28. 
Sanandaraj, H. S. \& Thomas, I. (1986) Certain correlates of self-esteem: A factor study. Psychological Studies, vol. 31, no. 2, pp. 119-124.

Schwartz, S. H., Cieciuch, J., Vecchione, M., Davidov, E., Fischer, R., Beierlein, C., Ramos, A., Verkasalo, M., Lönnqvist, J.-E., Demirutku, K., Dirilen-Gumus, O., \& Konty, M. (2012). Refining the theory of basic individual values. Journal of Personality and Social Psychology, vol. 103, pp. 663-688.

Smith, P.B., Trompenaars, F. and Dugan, S. (1995), The Rotter Locus of Control Scale in 43 Countries: A Test of Cultural Relativity. International Journal of Psychology, vol. 30, pp. 377-400.

Spector, A., Orrell, M., \& Davies, S. (2001). Can reality orientation be rehabilitated? Development and piloting of an evidencebased programme of cognition-based therapies for people with dementia. Neuropsychological Rehabilitation, vol. 11, pp. 377-397.

Streiner, D.L. (2003) Starting at the beginning: An introduction to coefficient alpha and internal consistency. Journal of Personality Assessment, vol. 80, pp. 99-103.

Tang, T.L., \& Gilbert, P.R. (1994) Organization-based self-esteem among mental health workers: A replication and extension. Public Personnel Management, vol. 23, no. 1, 127-134.

Tang, T.L., Kim, J.K., \& O'Donald, D.A. (2000) Perceptions of Japanese organizational culture: Employees in non-unionized Japanese-owned and unionized US-owned automobile plants. Journal of Managerial Psychology, vol. 15, no. 6, pp. 535-559.

Tarigani, V. \& Ariani, D.W. (2015) Empirical Study Relations Job Satisfaction, Organizational Commitment, and Turnover Intention. Advances in Management \& Applied Economics, vol. 15, no. 2, pp. 21-42. 
The Nation (2013, August 23). Study highlights factors behind labour woes, http:// www.nationmultimedia.com/business/Study-highlights-factors-behind-labourwoes-30213241.html.[14 July 2017].

Turongsomboon, W., \& Pillai, J. (2016, October) Thailand Compensation and Benefit Trends 2016: Voluntary Turnover Rates Soar as Performance Pressure Mounts.Aon Hewitt Thailand. https://apac.aonhewitt.com/home/about/media-room/press-releases/ october-november-2016 [14 July 2017].

Twenge, J.M., Zhang, L. \& Im, C. (2004) It's beyond my control: a cross-temporal meta-analysis of increasing externality in locus of control, 1960-2002. Personality Socical Psychological Review, vol. 8, no. 3, pp. 308-319.

Twenge, J.M., Campbell, S.M., Hoffman, B.J. and Lance, C.E. (2010) Generational Differences in Work Values: Leisure and Extrinsic Values Increasing, Social and Intrinsic Values Decreasing. Journal of Management, vol. 36, pp. 1117-1141.

Üzümceker, E. (2016) The Limits of the use of Locus of Control in Industrial Psychology: A Critical evaluation. Psychological Thought, vol. 9, no. 1, pp. 149-158.

Van Dyne, L., \& Pierce, J.L. (2004) Psychological ownership and feelings of possession: three field studies predicting employee attitudes and organizational citizenship behavior. Journal of Organizational Behavior, vol. 25, pp. 439-459.

Vandenberghe, C., Stinglhamber, F., Bentein, K. \& Delhaise, T. (2001) An Examination of the Cross-Cultural Validity of a Multidimensional Model of Commitment in Europe. European Journal of Cross-Cultural Psychology, vol. 32, no. 3, pp. 322-347. 
Yiing, L., \& Ahmad, K.Z. (2008) The moderating effects of organizational culture on the relationships between leadership behaviour and organizational commitment and between organizational commitment and job satisfaction and performance. Leadership \& Organization Development Journal, vol. 30, no. 1, pp. 53-86.

Yousef, D.A. (2000) Organizational commitment: am mediator of relationships of leadership behavior with job satisfaction and performance in anon-western country. Journal of Managerial Psychology, vol. 15, no. 1, pp. 6-28. 